\title{
Association between contemporary hormonal contraception and ovarian cancer in women of reproductive age in Denmark: prospective, nationwide cohort study
}

\author{
Lisa Iversen, ${ }^{1}$ Shona Fielding, ${ }^{2}$ Øjvind Lidegaard, ${ }^{3}$ Lina S Mørch, ${ }^{3}$ Charlotte W Skovlund, ${ }^{3}$ \\ Philip C Hannaford ${ }^{1}$
}

\begin{abstract}
${ }^{1}$ Academic Primary Care, Institute of Applied Health Sciences, University of Aberdeen, Aberdeen AB25 2ZD, UK

${ }^{2}$ Medical Statistics Team, Institute of Applied Health Sciences, University of Aberdeen, Aberdeen, UK ${ }^{3}$ Rigshospitalet, Juliane Marie Centre, Department of Gynaecology, University of Copenhagen, Denmark Correspondence to: L Iversen l.iversen@abdn.ac.uk (ORCID 0000-0002-2524-5229)

Additional material is published online only. To view please visit the journal online.

Cite this as: $B M / 2018 ; 362: k 3609$ http://dx.doi.org/10.1136/bmj.k3609

Accepted: 30 July 2018
\end{abstract}

\begin{abstract}
OBJECTIVES

To investigate the association between contemporary combined hormonal contraceptives (including progestogen types in combined preparations and all progestogen-only products) and overall and specific types of ovarian cancer.
\end{abstract}

DESIGN

Prospective, nationwide cohort study.

SETTING

Denmark, 1995-2014.

\section{PARTICIPANTS}

All women aged 15-49 years during 1995-2014 were eligible. Women were excluded if they immigrated after 1995, had cancer (except non-melanoma skin cancer), had venous thrombosis, or were treated for infertility before entry (final study population included 1879227 women). Women were categorised as never users (no record of being dispensed hormonal contraception), current or recent users ( $\leq 1$ year after stopping use), or former users ( $>1$ year after stopping use) of different hormonal contraceptives.

\section{MAIN OUTCOME MEASURES}

Poisson regression was used to calculate relative risk of ovarian cancer among users of any contemporary combined hormonal contraceptives and by progestogen type in combined preparations and all progestogen-only products, including non-oral preparations. Separate analyses examined women followed up to their first contraception type switch and those with full contraceptive histories. Duration, time since last use, and tumour histology were examined and the population prevented fraction were calculated.

\section{WHAT IS ALREADY KNOWN ABOUT THIS TOPIC}

Previous research relating to the use of older and higher dose preparations of oestrogen containing older progestogens has shown a reduced risk of ovarian cancer in users of combined oral hormonal contraceptives

This reduced risk has been shown to persist for many years after stopping use of these combined oral contraceptives

\section{WHAT THIS STUDY ADDS}

In this large, prospective, population based study of women aged 15-49 years in Denmark, use of contemporary combined oral contraceptives containing newer progestogens was associated with a reduction in the risk of ovarian cancer

Few women in the study were exclusive users of progestogen-only contraceptives; therefore, evidence regarding progestogen-only contraceptives was limited, with no evidence of beneficial ovarian cancer effects among exclusive users of these products

\section{RESULTS}

During 21.4 million person years, 1249 incident ovarian cancers occurred. Among ever users of hormonal contraception, 478 ovarian cancers were recorded over 13344531 person years. Never users had 771 ovarian cancers during 8150250 person years. Compared with never users, reduced risks of ovarian cancer occurred with current or recent use and former use of any hormonal contraception (relative risk 0.58 (95\% confidence interval 0.49 to 0.68 ) and 0.77 (0.66 to 0.91), respectively). Relative risks among current or recent users decreased with increasing duration (from 0.82 (0.59 to 1.12) with $\leq 1$ year use to 0.26 ( 0.16 to 0.43$)$ with $>10$ years' use; $\mathrm{P}<0.001$ for trend). Similar results were achieved among women followed up to their first switch in contraceptive type. Little evidence of major differences in risk estimates by tumour type or progestogen content of combined oral contraceptives was seen. Use of progestogen-only products were not associated with ovarian cancer risk. Among ever users of hormonal contraception, the reduction in the age standardised absolute rate of ovarian cancer was 3.2 per 100000 person years. Based on the relative risk for the never use versus ever use categories of hormonal contraception (0.66), the population prevented fraction was estimated to be $21 \%$-that is, use of hormonal contraception prevented $21 \%$ of ovarian cancers in the study population.

\section{CONCLUSIONS}

Use of contemporary combined hormonal contraceptives is associated with a reduction in ovarian cancer risk in women of reproductive age-an effect related to duration of use, which diminishes after stopping use. These data suggest no protective effect from progestogen-only products.

\section{Introduction}

Hormonal contraception is popular. At least 100 million women worldwide use hormonal contraception every day. ${ }^{1}$ In 2012, an estimated 238719 women around the world were diagnosed with a new ovarian cancer and 151917 died from the condition. ${ }^{2}$ Survival from ovarian cancer is poorer than from many other cancers; with an overall, age standardised survival rate at five years of $30-40 \%$ worldwide, varying according to stage at diagnosis. ${ }^{3}$ Previous research has shown a reduced risk of ovarian cancer in users of combined oral contraceptives, an effect that persists for many years after stopping use. ${ }^{4-9}$ However, most of the evidence relates to the use of older and higher 
dose preparations of oestrogen containing older progestogens. Therefore, this evidence might not reflect the impact of substantial changes in hormonal contraception that have occurred over time. Such changes have occurred in formulations of combined oral contraceptives (notably reductions in oestrogen dose and the introduction of newer progestogens such as desogestrel, gestodene, and drospirenone), patterns of administration (continuous $v$ monthly cycles in which 21 days of combined hormonal contraception is followed by seven hormone-free days during which a withdrawal bleed occurs), new non-oral routes of administration, and an increased use of progestogenonly preparations. ${ }^{10}$

It is important for users of contemporary combined oral contraceptives to know whether they are likely to experience the same pattern of ovarian cancer benefit as users in the older studies, and whether a benefit is specific to any particular formulation. Users of other hormonal contraceptive methods (including progestogen-only oral contraceptives and the levonorgestrel releasing intrauterine system) also should know whether they are at a reduced risk of ovarian cancer. Such information is important for putting into context the risks of other known cancers linked to contemporary hormonal contraception, such as breast cancer. ${ }^{11}$ Current evidence is insufficient for combined oral contraception ${ }^{4-9}$ as well as for other types of hormonal contraception. ${ }^{12-16}$ We report here a large investigation of contemporary hormonal contraceptive use and ovarian cancer in a national cohort of young Danish women.

\section{Methods}

\section{Data linkage}

The Danish Sex Hormone Register Study, which has been described previously, ${ }^{17}{ }^{18}$ follows a national cohort of women aged 15-79 years. It was established to investigate the relation between hormone use and the risk of cancer or cardiovascular disease. The study dataset uses an individual's personal identification number in the Civil Registration System to link data from several national registries:

- Statistics Denmark, for education information

- National Register of Medicinal Product Statistics, for hormonal contraceptive prescriptions dispensed since January 1994 and considered complete since 1 January 1995

- Danish Cancer Registry, for histologically verified cancers since 1943 and family history of premenopausal (age $<50$ years) breast or ovarian cancer in mothers or sisters

- National Birth Register, for all births since 1973 and information on smoking status (since 1991) and body mass index (since 2004)

- National Health Register, for hospital discharge diagnoses and surgeries since 1977.

The personal identification number system, in use since 1968, assigns a unique number to each resident in Denmark and is used as a key personal identifier in all national registries, thereby ensuring accurate linkage of different databases.

\section{Study population}

All women living in Denmark aged 15-49 years from 1 January 1995 to 31 December 2014 were eligible for the study unless they immigrated after 1995 (total number eligible=1904094). Women were excluded if they had cancer (except non-melanoma skin cancer), had venous thrombosis, or were treated for infertility before study entry (indicated by a redeemed prescription for ovarian stimulating drugs, Anatomical Therapeutic Chemical Classification (ATC) system code MG03G in the National Prescription Registry). The final study population comprised 1879227 women. The women were followed up to first diagnosis of ovarian cancer (ICD-10 (international classification of diseases, 10th revision) ${ }^{19}$ code $\mathrm{C} 56$ ), death, emigration, age 50 years, or end of follow-up (31 December 2014), whichever came first. During follow-up, women were censored permanently at the date of diagnosis of nonovarian cancer (except non-melanoma skin cancer), infertility treatment, venous thrombosis, bilateral oophorectomy, or second unilateral oophorectomy. Women were censored temporarily during pregnancy and for six months after delivery.

\section{Hormonal contraception}

Information about redeemed prescriptions included date of redemption, ATC code, dose, number of packages, defined daily doses, and route of administration. These data were updated daily to allow identification of when women started use (date when prescription was redeemed), stopped use (estimated date when prescription finished, based on number of packs issued), or switched use of hormonal contraception (redemption date of prescription for a different product). Using the methods of Nielsen and colleagues, ${ }^{20}$ gaps between prescriptions of fewer than 28 days were filled in prospectively. We assumed that the levonorgestrel intrauterine system was used for four years unless another hormonal contraceptive product was redeemed or pregnancy occurred before the end of the four year period. Women were categorised as never users (no record of being dispensed hormonal contraception), current or recent users (up to one year after stopping use), or former users (more than one year after stopping use) of different hormonal contraceptives.

\section{Statistical analysis}

We calculated age standardised incidence rates of ovarian cancers per 100000 person years, using the age distribution of the cohort as standard. Risk of ovarian cancer among users of the different product groups was analysed by a Poisson regression model in SAS version 9.3 (SAS Institute). Adjusted incidence rate ratios (referred to here as relative risks) and their surrounding 95\% confidence intervals were calculated for each model, with never users as the reference 
group. The adjusted models included the following time varying covariates:

- Calendar year

- Hormonal contraceptive use

- Parity $(0,1,2,3,4,>4)$

- Age group (15-19, 20-24, 25-29, 30-34, 35-39, 4044, 45-49 years)

- Education (elementary school only, high school only, further education excluding college/university, college/university education, university education with research qualifications, unknown)

- Tubal sterilisation (yes, no)

- Hysterectomy (yes, no)

- Endometriosis (yes, no)

- Polycystic ovary syndrome (yes, no)

- Family history of breast or ovarian cancer (yes, no).

Additional models adjusting for smoking status (current smoker, non-smoker, unknown at the time smoking status was ascertained antenatally) and body mass index when ascertained antenatally $(<18.5$, 18.5-25, $>25-30,>30$, unknown), were carried out in the subset of parous women with this information.

The main analysis compared ever users, former users, and current or recent users of any hormonal contraception with never users as reference. Separate analyses stratified the data by duration of use, by time since last current use, and by ovarian tumour histology. Ovarian tumour histology used the same groupings as the Collaborative Group on Epidemiological Studies of Ovarian Cancer, ${ }^{4}$ and used the following ICD-O-3 codes $^{21}$ : epithelial clear cell (M8310/8313), epithelial endometrioid (M8380), epithelial mucinous (M8470/8480/8490), and epithelial serous (M8441/8460); non-epithelial (M8620/8631/8650/8 $862 / 8890 / 8933 / 8951 / 8963 / 9080 / 9084 / 9110)$; and malignant tumour not otherwise specified (all other morphology codes supplied alongside the C56 cancer registration) and ending with the behaviour invasive digit 3. We tested for the trends for duration of use and time since last current use by including the duration/ time since variables as an ordinal variable, with values set to the median duration within each category. ${ }^{22}$

Comparisons between main contraceptive groupings were also conducted for women followed up to their first change in hormonal contraception, for those aged 15 years on or after 1 January 1995 (that is, those with a fully documented hormonal contraceptive history), and for epithelial ovarian cancers only. Previous studies have indicated a persisting protective effect from previous use of oral combined contraception. ${ }^{4}$ 69 To minimise the effects of previous use while ensuring that we had sufficient data for analysis, our risk estimates for different hormonal preparations were derived mainly among women followed up to their first change in hormonal contraception during the study. Up to 31 December 2003, tumour staging in the Danish Cancer Registry used the International Federation of Gynaecology and Obstetrics (FIGO) staging classification, ${ }^{23}$ after which the Union for International Cancer Control Tumour, Node, Metastasis
(TNM) classification was used. ${ }^{24}$ When necessary, we converted TNM classification information into the FIGO stage classification. ${ }^{25}$ We then examined tumour FIGO stage by age at diagnosis and calculated the frequency of the different tumour types by stage at diagnosis. We calculated the population prevented fraction (population prevented fraction=prevalence exposure $(1-$ relative risk)) associated with ever use of any hormonal contraception by using the relative risk of never use versus ever use of any hormonal contraception. The population prevented fraction is the proportion (expressed as a percentage) of the ovarian cancers in the cohort that has been prevented by ever use of any hormonal contraception.

\section{Patient and public involvement}

Patients or members of the public were not invited to comment on the research question, study design, or to interpret the results. Since this was a population study using existing data, asking them to share patient relevant outcomes was not possible. They were not invited to contribute to the writing or editing of this document for readability or accuracy. The results will be shared with the media and disseminated to members of the public through appropriate media channels.

\section{Results}

During the 20 year study period, 1249 women aged 15-49 years had incident ovarian cancer during more than 21.4 million person years of observation (about 11.4 years per woman). At study entry, 756943 women younger than 20 years then had a mean follow-up of 10.8 years (standard deviation 6.0), 379808 aged 20-29 years had a mean follow-up of 16.8 (5.0) years, 373167 aged 30-39 years had a mean follow-up of 13.8 (4.2) years, and 369309 aged 40 years and older had a mean follow-up of 4.7 (2.9) years. During 13344531 person years of follow-up, 478 ovarian cancers were found among ever users of any hormonal contraception. In never users, 771 ovarian cancers occurred during 8150250 person years. Median age at ovarian cancer diagnosis was 44.4 years (interquartile range 38.9-47.7). Most hormonal contraceptive use was related to combined oral contraception $(86 \%$, $7612267 / 8839374$ person years of current or recent use; table 1). Current or recent users of the levonorgestrel intrauterine system were older and more likely to be parous than women using other products. Generally, a higher percentage of parous women were using non-oral routes of hormonal contraception or oral progestogen-only products than nulliparous women. Few women (contributing about 2-3\% of total person years) had a family history of early (before age 50 years) ovarian or breast cancer.

The age adjusted incidence of ovarian cancer was highest in women who were never users of hormonal contraception (7.5 per 100000 person years; table 2). Among ever users of hormonal contraception, reduction in the age standardised absolute rate of ovarian cancer 


\begin{tabular}{|c|c|c|c|c|c|c|c|c|c|c|c|c|}
\hline \multirow{2}{*}{$\begin{array}{l}\text { Type of hormonal } \\
\text { contraception (dates } \\
\text { on market during study*) }\end{array}$} & \multirow{2}{*}{$\begin{array}{l}\text { No of } \\
\text { person } \\
\text { years }\end{array}$} & \multirow{2}{*}{$\begin{array}{l}\text { Age (years; } \\
\text { mean (SD)) }\end{array}$} & \multicolumn{2}{|c|}{$\begin{array}{l}\text { Education } \\
(\%)+\end{array}$} & \multirow{2}{*}{$\begin{array}{l}\text { Nulliparous } \\
\text { (\%) }\end{array}$} & \multirow{2}{*}{$\begin{array}{l}\text { PCOS } \\
\text { (\%) }\end{array}$} & \multirow{2}{*}{$\begin{array}{l}\text { Tubal } \\
\text { sterilisation } \\
\text { (\%) }\end{array}$} & \multirow{2}{*}{$\begin{array}{l}\text { Hysterectomy } \\
\text { (\%) }\end{array}$} & \multirow{2}{*}{$\begin{array}{l}\text { Endometriosis } \\
\text { (\%) }\end{array}$} & \multirow{2}{*}{$\begin{array}{l}\text { Family } \\
\text { history } \\
\text { (\%)‡ }\end{array}$} & \multirow{2}{*}{$\begin{array}{l}\text { BMI } \\
\text { (mean } \\
(S D) \S\end{array}$} & \multirow{2}{*}{$\begin{array}{l}\text { Smoking } \\
(\%) \uparrow\end{array}$} \\
\hline & & & $E$ & $\mathrm{U}$ & & & & & & & & \\
\hline \multicolumn{13}{|l|}{ Main use groups } \\
\hline Never use & 8150250 & $35.4(11.8)$ & 22.5 & 5.4 & 86.3 & 0.1 & 6.9 & 2.6 & 0.4 & 2.3 & $24.6(5.3)$ & 21.5 \\
\hline Former use, $>12$ months ago & 4505157 & $36.8(8.0)$ & 18.0 & 9.4 & 46.7 & 0.3 & 9.9 & 2.2 & 1.0 & 2.8 & $24.2(5.0)$ & 24.5 \\
\hline Current or recent use & 8839374 & $29.2(8.3)$ & 14.3 & 7.1 & 74.8 & 0.2 & 1.1 & 0.2 & 0.4 & 2.5 & $24.4(5.0)$ & 24.7 \\
\hline \multicolumn{13}{|c|}{ Current or recent use of combined hormonal contraception } \\
\hline \multicolumn{13}{|l|}{ Oral, $50 \mu \mathrm{g}$ ethinylestradiol } \\
\hline Norethisterone (1995-2002) & 57516 & $32.3(8.7)$ & 32.6 & 2.0 & 89.4 & 0.03 & 2.7 & 0.3 & 0.2 & 2.5 & $24.8(5.5)$ & 46.6 \\
\hline Levonorgestrel (1995-2009) & 82756 & $34.6(9.5)$ & 31.4 & 3.5 & 86.5 & 0.06 & 3.3 & 0.4 & 0.5 & 2.5 & $24.9(5.4)$ & 45.9 \\
\hline \multicolumn{13}{|l|}{ Oral, $20-40 \mu \mathrm{g}$ ethinylestradiol } \\
\hline Norethisterone (1995-) & 165211 & $28.2(7.7)$ & 21.9 & 4.0 & 86.6 & 0.04 & 1.0 & 0.1 & 0.1 & 2.8 & $25.1(5.3)$ & 31.9 \\
\hline Levonorgestrel (1995-) & 1016015 & $30.5(8.8)$ & 15.7 & 6.0 & 77.1 & 0.2 & 0.9 & 0.1 & 0.3 & 2.3 & $24.5(5.0)$ & 27.6 \\
\hline Norgestimate (1995-) & 721004 & $27.9(7.8)$ & 14.8 & 6.5 & 78.3 & 0.2 & 0.9 & 0.1 & 0.3 & 2.4 & $24.6(5.1)$ & 27.8 \\
\hline Desogestrel (1995-) & 1659258 & $27.6(7.9)$ & 13.6 & 6.8 & 79.8 & 0.1 & 0.7 & 0.1 & 0.4 & 2.4 & $24.5(5.0)$ & 26.2 \\
\hline Gestodene (1995-) & 2985909 & $27.7(7.8)$ & 14.2 & 6.3 & 79.7 & 0.1 & 0.7 & 0.1 & 0.3 & 2.4 & $24.7(5.1)$ & 26.5 \\
\hline Drospirenone (2001-) & 592556 & $26.6(7.8)$ & 9.8 & 8.8 & 78.4 & 0.5 & 0.7 & 0.1 & 0.5 & 2.3 & $24.1(4.8)$ & 24.2 \\
\hline Cyproterone (1995-) & 317961 & $27.3(7.2)$ & 11.8 & 8.6 & 85.3 & 1.1 & 0.7 & 0.1 & 0.3 & 2.3 & $23.7(4.8)$ & 28.0 \\
\hline $\begin{array}{l}\text { Estradiol valerate, dienogest } \\
(2009-)\end{array}$ & 14081 & $33.9(10.1)$ & 8.8 & 11.6 & 55.3 & 1.0 & 2.5 & 0.6 & 1.4 & 2.2 & $23.7(4.6)$ & 19.2 \\
\hline \multicolumn{13}{|l|}{ Non-oral } \\
\hline Patch (2003-) & 15358 & $27.0(7.7)$ & 18.6 & 4.4 & 63.6 & 0.5 & 1.0 & 0.1 & 0.6 & 1.7 & $23.8(4.9)$ & 28.3 \\
\hline Vaginal ring (2002-) & 124280 & $28.2(7.0)$ & 9.8 & 12.5 & 68.6 & 0.4 & 0.5 & 0.0 & 0.5 & 2.2 & $24.0(4.7)$ & 24.0 \\
\hline \multicolumn{13}{|c|}{ Current or recent use of progestogen-only products } \\
\hline \multicolumn{13}{|l|}{ Oral } \\
\hline Norethisterone (1995-) & 158073 & $34.8(8.3)$ & 17.4 & 9.2 & 57.7 & 0.1 & 1.1 & 0.2 & 0.4 & 2.8 & $23.9(4.7)$ & 20.0 \\
\hline Levonorgestrel (1995-2005) & 11544 & $37.6(8.3)$ & 22.1 & 7.9 & 80.1 & 0.0 & 1.1 & 0.3 & 0.1 & 2.9 & $24.2(4.5)$ & 18.3 \\
\hline Desogestrel (2001-) & 123539 & $32.4(8.3)$ & 10.8 & 12.7 & 45.1 & 0.1 & 1.2 & 0.1 & 0.4 & 2.9 & $24.0(4.8)$ & 18.5 \\
\hline \multicolumn{13}{|l|}{ Non-oral } \\
\hline MPA depot (1995-) & 27832 & $27.7(8.9)$ & 43.7 & 0.5 & 72.5 & 0.3 & 2.3 & 0.2 & 0.5 & 2.4 & $26.0(6.4)$ & 54.5 \\
\hline Implant (1999-) & 58371 & $26.9(8.4)$ & 24.2 & 2.7 & 68.4 & 0.3 & 1.6 & 0.2 & 0.3 & 2.1 & $25.3(5.8)$ & 35.4 \\
\hline LNG-IUS (1995-) & 708111 & $40.0(6.6)$ & 11.6 & 11.2 & 33.5 & 0.2 & 4.2 & 1.4 & 1.1 & 2.9 & $24.1(4.7)$ & 18.7 \\
\hline \multicolumn{13}{|c|}{$\begin{array}{l}\text { Descriptive statistics calculated as the average person time with a given characteristic divided by the total amount of person time on a specific hormonal contraceptive; descrip- } \\
\text { tive percentages represent the percentage of person time with a given characteristic. } \\
\text { BMI=body mass index; } E=\text { =elementary school; LNG-IUS=levonorgestrel intrauterine system; MPA=medroxyprogesterone acetate; PCOS; polycystic ovary syndrome; SD=standard } \\
\text { deviation; } U=\text { =university. } \\
\text { *From this year onwards to end of the study. } \\
\text { †Percentage of participants with elementary school education only and percentage with university education. } \\
\text { tFamily history of premenopausal breast or ovarian cancer. } \\
\text { \$Available since } 2004 \text { only in parous women ( } n=322641,73 \% \text { unknown body mass index). } \\
\text { १Available since } 1991 \text { only in parous women ( } n=512143,57 \% \text { unknown smoking). }\end{array}$} \\
\hline
\end{tabular}

was 3.2 per 100000 person years. Overall, ever users of any hormonal contraception had a reduced risk of ovarian cancer compared with never users (relative risk 0.66 (95\% confidence interval 0.58 to 0.76$)$ ). Reduced risk estimates were also observed for current or recent use of any hormonal contraception (0.58 (0.49 to $0.68)$ ) as well as for former use (0.77 (0.66 to 0.91$)$ ). Current or recent users of progestogen-only products seemed to have a smaller reduction in ovarian cancer risk than users of combined oral contraceptives. The reduced risk of ovarian cancer among current users was stronger with increasing duration of hormonal contraceptive use. The reduced ovarian cancer risk among previous hormonal contraceptive users diminished with time since stopping use, and was nonsignificant by 10 years after last use. When both time since last use and duration were examined, evidence among former users of any hormonal contraception indicated greater protection with longer durations of use and a suggestion that the protection waned more quickly in those with shorter durations of use (table 3).

Among women followed in the cohort up to their first switch in hormonal contraception $(71 \%$ of the total period of observation, 15333680 person years), there was little evidence of important differences between combined oral contraceptives containing different progestogens, at least for those with sufficient usage to produce precise risk estimates (table 4). In this analysis, progestogen-only products, including the levonorgestrel containing intrauterine system, did not protect against ovarian cancer. For combined products, the pattern of relative risks seen in the full cohort (that is, women followed beyond their first switch in hormonal contraception) were similar (table 1S). Overall similar risk estimates were found in both the full cohort and among parous women followed up to their first switch in hormonal contraception when we adjusted for smoking and body mass index (data not shown).

Restricting the analysis to women with a complete contraception exposure history (those aged 15 years on or after 1 January 1995) reduced the cohort to 596395 women (31.7\% of total number) contributing $25 \%$ of the total period of observation (5417268 person years) and $6 \%$ of all ovarian cancers, reflecting the younger age of this subset of women. Most of the risk 


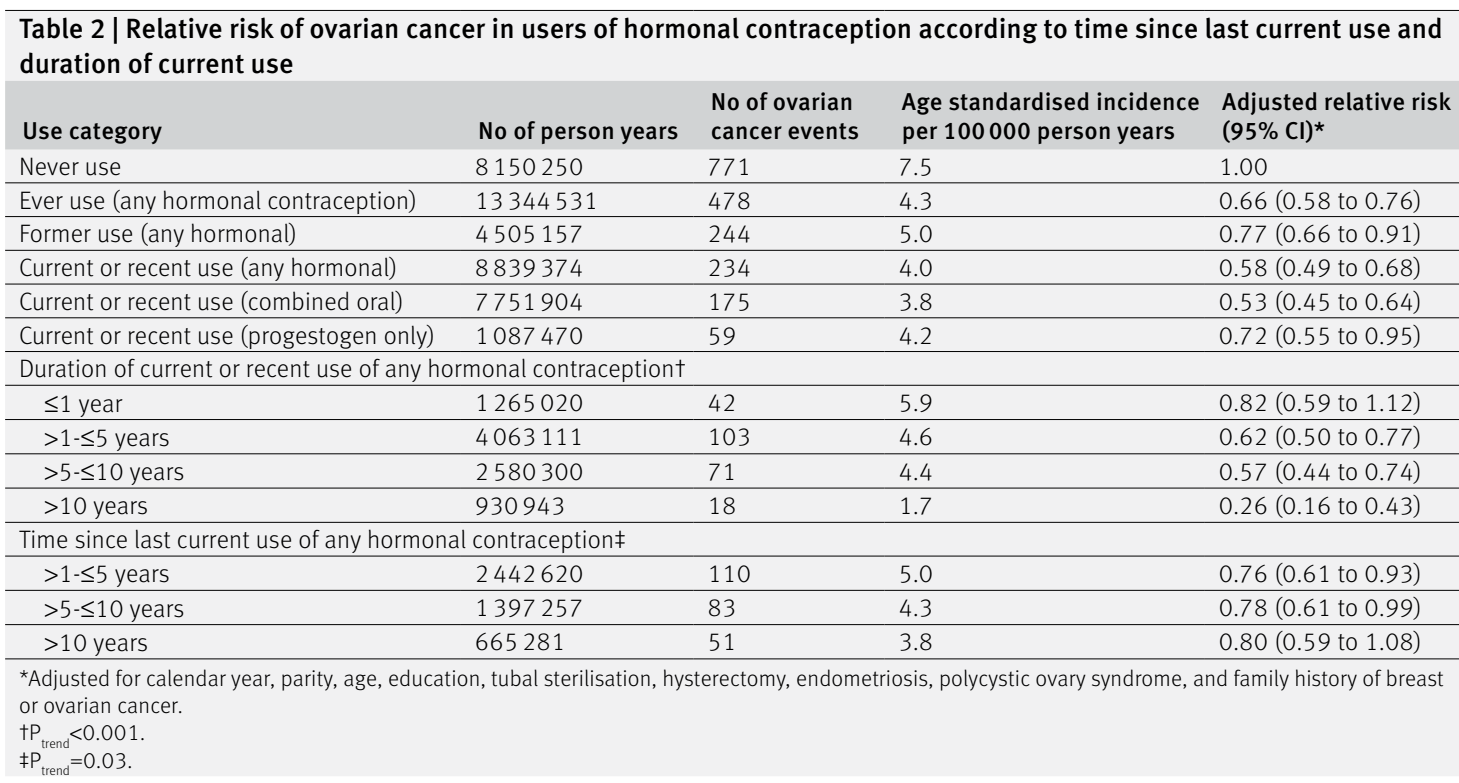

estimates were imprecise although broadly compatible with the results of the main analyses (table $2 \mathrm{~S}$ ).

Current or recent use of any hormonal contraception was associated with a reduced risk of any epithelial ovarian cancer, in particular endometrioid, mucinous, and serous epithelial cancer (table 5). There was not a significant reduction in clear cell epithelial or nonepithelial ovarian cancer. When the subset of epithelial ovarian cancers $(773 / 1064,73 \%$ of the total ovarian cancers) was examined among women followed up to their first switch in hormonal contraception (table $3 \mathrm{~S}$ ), the pattern of relative risks for different hormonal contraceptives was similar to that seen for all ovarian cancers.

Age at diagnosis was associated with FIGO stage with a higher percentage of women in the oldest age group being diagnosed at stage III or IV in comparison with younger women (table $4 \mathrm{~S} ; \mathrm{P}_{\text {trend }}<0.001$ ). Over 60\% $(323 / 502)$ of serous tumours were diagnosed at stage III or IV compared with 15\% (30/204) of mucinous tumours (table 5S). Based on the relative risk for the never use versus ever use categories of hormonal contraception (0.66), the population prevented fraction was estimated to be $21 \%$-that is, use of hormonal contraception prevented $21 \%$ of ovarian cancers in the study population.

\section{Discussion}

\section{Principal findings}

In this study of women of reproductive age (that is, younger than 50 years) living in Denmark, we found that ever use of any contemporary hormonal contraception was associated with a reduced risk of ovarian cancer, an effect that strengthened with longer periods of current use and persisted for several years after stopping use. Most of the hormonal contraceptive use related to combined oral contraceptives. There was little evidence of important differences between combined oral contraceptives containing different types of progestogens. The reduced risk associated with hormonal contraception was seen with nearly all types of ovarian cancer. Our data do not suggest a protective effect from progestogen-only products; however, few women were exclusive users of such products, and so we had limited statistical power to detect such an effect.

\section{Strengths and limitations of study}

Strengths of our study included its nationwide coverage of nearly 1.9 million women, more than 21 million person years of prospective follow-up, and the examination of the many different forms of hormonal contraception currently available. The linkage of prescribing and cancer registration information avoided recall bias regarding patterns of hormonal contraception use. Similar to most studies of hormonal contraceptives, we have assumed that women who were dispensed a prescription subsequently used it. If some women did not (that is, they remained being a non-user when we incorrectly deemed them to be a user), such misclassification would underestimate the protective effects found. However, because of the time varying variables used in our study, this misclassification of current use would only be present for the time period of the redeemed prescription. Thereafter, the women would be classified as a non-taker.

The data linkage study design also enabled us to adjust for several important confounding variables. The cohort was younger than 50 years, and so few women will have used hormone replacement therapy known to increase ovarian cancer risk. ${ }^{26}$ While this age restriction meant that we could be confident that we were examining the effects of oral contraception, it also meant that the study could not provide information on how contemporary hormonal contraceptives affected ovarian cancer risk in older women, in whom most cases of ovarian cancer occur. We were not able to adjust for some factors, such as breastfeeding, and 


\begin{tabular}{|c|c|c|c|c|c|c|c|c|c|}
\hline \multirow[b]{3}{*}{ Duration of use } & \multicolumn{9}{|c|}{ Time since last current use of hormonal contraception } \\
\hline & \multicolumn{3}{|l|}{$1-<5$ years } & \multicolumn{3}{|l|}{$5-<10$ years } & \multicolumn{3}{|l|}{$\geq 10$ years } \\
\hline & $\begin{array}{l}\text { No of person } \\
\text { years }\end{array}$ & $\begin{array}{l}\text { No of ovarian } \\
\text { cancer events }\end{array}$ & $\begin{array}{l}\text { Relative risk } \\
(95 \% \mathrm{Cl})^{\star}\end{array}$ & $\begin{array}{l}\text { No of person } \\
\text { years }\end{array}$ & $\begin{array}{l}\text { No of ovarian } \\
\text { cancer events }\end{array}$ & $\begin{array}{l}\text { Relative risk } \\
(95 \% \mathrm{CI})^{\star}\end{array}$ & $\begin{array}{l}\text { No of person } \\
\text { years }\end{array}$ & $\begin{array}{l}\text { No of ovarian } \\
\text { cancer events }\end{array}$ & $\begin{array}{l}\text { Relative risk } \\
(95 \% \mathrm{Cl})^{\star}\end{array}$ \\
\hline$\leq 1$ year & 667835 & 37 & $\begin{array}{l}0.81 \\
(0.58 \text { to } 1.13)\end{array}$ & 470243 & 45 & $\begin{array}{l}1.14 \\
\text { (0.84 to } 1.56)\end{array}$ & 316850 & 27 & $\begin{array}{l}0.81 \\
(0.54 \text { to } 1.21)\end{array}$ \\
\hline$>1-\leq 5$ years & 1038886 & 47 & $\begin{array}{l}0.84 \\
(0.62 \text { to } 1.15)\end{array}$ & 635891 & 29 & $\begin{array}{l}0.66 \\
(0.45 \text { to } 0.98)\end{array}$ & 308126 & 22 & $\begin{array}{l}0.76 \\
(0.48 \text { to } 1.20)\end{array}$ \\
\hline$>5$ years & 735899 & 26 & $\begin{array}{l}0.60 \\
(0.39 \text { to } 0.91)\end{array}$ & 291123 & 9 & $\begin{array}{l}0.41 \\
(0.21 \text { to } 0.81)\end{array}$ & 40304 & 2 & $\begin{array}{l}0.57 \\
(0.14 \text { to } 2.33)\end{array}$ \\
\hline
\end{tabular}

*Adjusted for calendar year, parity, age, education, tubal sterilisation, hysterectomy, endometriosis, polycystic ovary syndrome, and family history of breast or ovarian cancer.

information about endometriosis and polycystic ovary syndrome only related to women admitted to hospital for these conditions. Our findings, therefore, could be subject to residual confounding. Information on smoking and body mass index was only available in parous women for part of the study period. However, adjustment for these variables in the subset of women for whom these data were available did not materially change the risk estimates.

The low incidence of ovarian cancer among women followed up to their first switch in type of hormonal contraception meant that it was not possible to examine the association between duration of use and time since last current use among users of specific preparations. However, given the little evidence overall of major differences between preparations, it seems unlikely that there are important differences in these temporal associations.
We did not have information about hormonal contraceptives prescribed before entry to the study. Some women who were classified as never users could have used hormonal contraception previously. Such misclassification would underestimate the protective risk estimates, a problem that should diminish the further a woman was from her last use. Because older women are further away from their last use, and because most instances of ovarian cancer occur in older women $(71 \%$ of our events were in women older than 40 years), we do not believe that our results were seriously affected by this misclassification. Some of the effects attributed to the use of a particular product could reflect lingering effects from the use of a previous product or products. Our analysis of women followed to their first switch of hormonal contraception in the study was intended to minimise such effects, while still providing enough data for reliable risk estimates. Little

Table 4 | Relative risk of ovarian cancer in users by different types of hormonal contraception in women followed up to their first switch in hormonal contraception (that is, the no change cohort)

\begin{tabular}{|c|c|c|c|}
\hline & No of person years & No of cancer events & Adjusted relative risk $(95 \% \mathrm{Cl})^{*}$ \\
\hline Never use & 8150250 & 771 & 1.00 \\
\hline Ever use (any hormonal contraception) & 7183430 & 293 & $0.73(0.63$ to 0.84$)$ \\
\hline Former use (any hormonal) & 2590322 & 164 & 0.85 (0.71 to 1.02$)$ \\
\hline Current or recent use (any hormonal) & 4593109 & 129 & $0.61(0.50$ to 0.74$)$ \\
\hline Current or recent use (combined OC) & 4316888 & 103 & $0.56(0.45$ to 0.70$)$ \\
\hline Current or recent use (progestogen only) & 276221 & 26 & $0.87(0.59$ to 1.29$)$ \\
\hline \multicolumn{4}{|c|}{ Current or recent use of combined hormonal contraception-oral } \\
\hline Norethisterone, $50 \mu \mathrm{g}$ ethinylestradiol & 36494 & 4 & $1.35(0.50$ to 3.61$)$ \\
\hline Levonorgestrel, $50 \mu \mathrm{g}$ ethinylestradiol & 47335 & 6 & $1.21(0.54$ to 2.71$)$ \\
\hline Norethisterone, $30-35 \mu \mathrm{g}$ ethinylestradiol & 116090 & 7 & $1.30(0.62$ to 2.76$)$ \\
\hline Levonorgestrel, $30-35 \mu \mathrm{g}$ ethinylestradiol & 519113 & 11 & $0.33(0.18$ to 0.61$)$ \\
\hline Desogestrel, $20-30 \mu \mathrm{g}$ ethinylestradiol & 988952 & 17 & $0.45(0.27$ to 0.73$)$ \\
\hline Gestodene, $20-35 \mu \mathrm{g}$ ethinylestradiol & 1887047 & 42 & $0.57(0.41$ to 0.79$)$ \\
\hline Drospirenone, $20-35 \mu \mathrm{g}$ ethinylestradiol & 188928 & 5 & $1.08(0.44$ to 2.64$)$ \\
\hline Norgestimate, $35 \mu \mathrm{g}$ ethinylestradiol & 375778 & 11 & $0.75(0.41$ to 1.37$)$ \\
\hline Cyproterone, $30 \mu \mathrm{g}$ ethinylestradiol & 142147 & 0 & - \\
\hline Estradiol valerate, dienogest & 1022 & 0 & - \\
\hline \multicolumn{4}{|c|}{ Current or recent use of combined hormonal contraception-non-oral } \\
\hline Patch & 2253 & 0 & - \\
\hline Vaginal ring & 11729 & 0 & - \\
\hline \multicolumn{4}{|c|}{ Current or recent use of progestogen-only contraception-oral } \\
\hline Norethisterone & 66934 & 4 & $0.62(0.23$ to 1.64$)$ \\
\hline Levonorgestrel & 6972 & 1 & $1.16(0.16$ to 8.23$)$ \\
\hline Desogestrel & 12155 & 0 & - \\
\hline \multicolumn{4}{|c|}{ Current or recent use of progestogen-only contraception-non-oral } \\
\hline MPA depot & 7321 & 3 & $6.56(2.11$ to 20.40$)$ \\
\hline Implant & 10575 & 0 & - \\
\hline LNG-IUS & 172265 & 18 & 0.84 (0.53 to 1.35$)$ \\
\hline
\end{tabular}

LNG-IUS=levonorgestrel intrauterine system; MPA=medroxyprogesterone acetate.

*Adjusted for calendar year, parity, age, education, tubal sterilisation, hysterectomy, endometriosis, polycystic ovary syndrome, and family history of breast or ovarian cancer. 


\begin{tabular}{|c|c|c|c|}
\hline Histology and use category & No of person years & No of cancer events & Adjusted relative risk $(95 \% \mathrm{Cl})^{*}$ \\
\hline \multicolumn{4}{|l|}{ Epithelial ovarian cancer } \\
\hline Any epithelial ovarian cancer & - & 902 & - \\
\hline Never use & 8150250 & 566 & 1.00 \\
\hline Current or recent use & 8839374 & 155 & $0.58(0.47$ to 0.70$)$ \\
\hline Former use & 4505157 & 181 & 0.75 (0.62 to 0.91$)$ \\
\hline Clear cell epithelial ovarian cancer & - & 61 & - \\
\hline Never use & 8150250 & 41 & 1.00 \\
\hline Current or recent use & 8839374 & 9 & $0.59(0.28$ to 1.27$)$ \\
\hline Former use & 4505157 & 11 & $0.68(0.32$ to 1.41$)$ \\
\hline Endometrioid epithelial ovarian cancer & - & 135 & - \\
\hline Never use & 8150250 & 93 & 1.00 \\
\hline Current or recent use & 8839374 & 21 & $0.58(0.35$ to 0.96$)$ \\
\hline Former use & 4505157 & 21 & $0.64(0.38$ to 1.06$)$ \\
\hline Mucinous epithelial ovarian cancer & - & 204 & - \\
\hline Never use & 8150250 & 107 & 1.00 \\
\hline Current or recent use & 8839374 & 45 & 0.65 (0.44 to 0.97$)$ \\
\hline Former use & 4505157 & 52 & $0.96(0.65$ to 1.41$)$ \\
\hline Serous epithelial ovarian cancer & - & 502 & - \\
\hline Never use & 8150250 & 325 & 1.00 \\
\hline Current or recent use & 8839374 & 80 & $0.55(0.42$ to 0.72$)$ \\
\hline Former use & 4505157 & 97 & $0.72(0.56$ to 0.93$)$ \\
\hline \multicolumn{4}{|l|}{ Non-epithelial ovarian cancer } \\
\hline No of ovarian cancer events & - & 73 & - \\
\hline Never use & 8150250 & 33 & 1.00 \\
\hline Current or recent use & 8839374 & 21 & 0.64 (0.34 to 1.20$)$ \\
\hline Former use & 4505157 & 19 & 1.09 (0.57 to 2.08$)$ \\
\hline \multicolumn{4}{|l|}{ Malignant tumour not otherwise specified } \\
\hline No of ovarian cancer events & - & 274 & - \\
\hline Never use & 8150250 & 172 & 1.00 \\
\hline Current or recent use & 8839374 & 58 & $0.57(0.41$ to 0.80$)$ \\
\hline Former use & 4505157 & 44 & $0.73(0.50$ to 1.05$)$ \\
\hline
\end{tabular}

evidence of important differences was seen between the combined oral contraceptives. Furthermore, when we restricted our analysis to women with complete contraceptive histories (in whom misclassification from unknown previous use could not occur), the pattern of results for individual combinations was similar, albeit with imprecise, non-significant risk estimates.

\section{Comparison with other studies}

By contrast with most previous research, our study included women aged 15-49 years, most of whom will have been premenopausal. Thus, the periods of observation for ever users of hormonal contraceptives in this age group had a higher proportion of information relating to current or recent use than those for ever users in a study recruiting older women, because many would have stopped using hormonal contraception many years previously. The Collaborative Group on Epidemiological Studies of Ovarian Cancer's reanalysis of oral contraception data from 45 studies included women who were generally older than our cohort (mean age of diagnosis of ovarian cancer was 56 years, with only $18 \%$ of tumours diagnosed in women younger than 45 years). ${ }^{4}$ The overall relative risk between ever and never users was 0.73 (95\% confidence interval 0.70 to 0.76 ). The Collaborative Group's analysis found that younger and premenopausal women seemed to have greater percentage reductions in risk of ovarian cancer per five years of oral contraceptive use. ${ }^{4}$ However, after accounting for time since last use, no significant heterogeneity by menopausal status or age was seen, demonstrating that how recent a woman last used hormonal contraceptives was more important than the other two factors. Our slightly stronger reduced risk for any ovarian cancer among ever users of any hormonal contraception (relative risk 0.66 (95\% confidence interval 0.58 to 0.76 )) was possibly due to $58 \%$ of the total period of observation in ever users arising from current or recent use of combined oral contraceptives.

Similar to the Collaborative Group ${ }^{4}$ and other more recent investigations, ${ }^{5-9}$ we found that the risk reductions among current users of any hormonal contraception got stronger with longer durations of use and persisted for a number of years after stopping use. The apparent loss of protection 10 years after stopping hormonal contraception could be due to the loss of biological effect (assuming a causal association exists), or reduced statistical power to continue to observe a significant reduction due to the relatively small periods of observation ( $7 \%$ of total person years for ever use).

Studies ${ }^{4}$ have not found differences in ovarian cancer risk by oestrogen dose of combined oral contraceptives (when assessed by decade of use). The same studies were unable to investigate associations with combined pills containing different progestogens. 
The Nurses' Health Study II reported that short term use of preparations containing the oestrogen mestranol (hazard ratio $1.83,95 \%$ confidence interval 1.16 to 2.88) and first generation progestogens (1.72, 1.11 to 2.65 ) were associated with an increased ovarian cancer risk, but found no relation with those containing second generation progestogens (levonorgestrel and norgestrel). ${ }^{22}$ The Nurses' study had insufficient data to provide risk estimates for products containing desogestrel, norgestimate, or drospirenone.

Although we lacked power to examine patterns of risk by duration of use and progestogen type, we had good statistical power for the most often used progestogens and found little evidence of important differences in overall ovarian cancer risk among current or recent users of combined preparations containing different progestogens. It has been suggested that combined oral contraceptives do not differ from progestogen-only pills in their risk of ovarian cancer. ${ }^{27}$ In our study, current or recent use of progestogen-only products among all women implied a smaller effect on ovarian cancer risk estimates, compared with users of combined products (table 2). In the no change cohort followed up to the first switch in hormonal contraception, no protection against ovarian cancer was seen in users of progestogenonly products (table 4). This risk estimate was based on only 26 events, and so had limited statistical power to detect a significant protective effect. Alternatively, the lack of significance could be because of an absence of biological effect from progestogen-only products, with the reduced risk estimates seen in the full cohort analysis due to lingering effects from previous combined pill usage, suggesting that the protection found in the full cohort analysis could be due to a lingering effect from previous combined pill usage.

Few studies have examined use of depot medroxyprogesterone, ${ }^{14-16}$ with findings from those studies able to investigate exclusive use ${ }^{14} 16$ suggesting a protective effect. Our finding of an increased risk was based on only three exposed ovarian cancers and a very small total observation period, resulting in very imprecise risk estimates.

Soini and colleagues ${ }^{12} 13$ reported a standardised incidence ratio of 0.60 (95\% confidence interval 0.45 to 0.76 ) for ovarian cancer and use of the levonorgestrel intrauterine system among women in Finland, ${ }^{12}$ with decreased risks for mucinous, endometrioid, and serous ovarian carcinomas. ${ }^{13}$ Our findings do not concur with those studies, possibly because the Finnish studies did not adjust for parity or previous use of oral contraceptives (shown to have a persisting protective effect).

The Ovarian Cancer Cohort Consortium (OC3) recently examined risk factors for different histological types of ovarian cancer among more than 1.2 million women from 21 prospective studies in Europe, Asia, and North America. The consortium found that a five year increase in duration of oral contraceptive use and more than 10 years of use were both associated with a decreased risk of serous, endometrioid, and clear cell tumours but not mucinous tumours. ${ }^{28}$ Similarly, the Collaborative Group on Epidemiological Studies of Ovarian Cancer found that oral contraceptive use was not associated with the incidence of mucinous tumours. ${ }^{4}$ It is important to note that our study investigated women of reproductive age and who were younger than those in both the OC3 (median age at diagnosis 61.3-68.9 years depending on histological tumour type) and Collaborative Group (mean age at diagnosis 56 years) studies.

Our findings suggest that the protective effects of current or recent use of hormonal contraception is similar among endometrioid, mucinous and serous types of epithelial ovarian cancer. In line with current understanding, most mucinous tumours in our study were diagnosed at FIGO stage I. ${ }^{29}$ However, only 3\% of all ovarian cancers are now thought to be mucinous types, ${ }^{29}$ indicating a relatively high incidence of mucinous tumours in our cohort. This high incidence of mucinous tumours has been observed previously in Denmark ${ }^{30}$ and elsewhere, ${ }^{28}$ and it is widely recognised that improvements in pathology, imaging, and serum markers will alter the reporting of the morphological subtypes of ovarian cancer. ${ }^{29}$ Therefore, some of the epithelial tumours could have been misclassified as mucinous. ${ }^{30}$ Recent understanding suggests that although ovarian cancer is clinically considered to be one disease, it is in fact a heterogeneous group of neoplasms with different pathogenesis pathways. $^{29}$ Combined hormonal contraceptives suppress ovulation so protection against neoplastic development is feasible, but the exact mechanisms by which hormonal contraceptives reduce ovarian cancer risk are unclear. Whatever the biological mechanisms, the epidemiological evidence suggests a longlasting protection against most types of ovarian cancer from combined oral contraception. ${ }^{428}$

It has been suggested that recent downward trends in ovarian cancer mortality rates in North America and Europe can be partly attributed to the use of combined oral contraceptives. ${ }^{31}$ We found a population prevented fraction of $21 \%$ with use of hormonal contraception, which supports the notion that these ovarian cancer mortality benefits are likely to continue.

\section{Conclusions}

Based on results from our prospective study, contemporary combined hormonal contraceptives are still associated with a reduced risk of ovarian cancer in women of reproductive age, with patterns similar to those seen with older combined oral products. The reduced risk seems to persist after stopping use, although it is not yet known how long for. Presently, there is insufficient evidence to suggest similar protection among exclusive users of progestogen-only products.

Contributors: $\mathrm{LI}$ conducted the literature review and wrote the first draft and subsequent revisions of the paper with input from all authors; she is guarantor for the paper. SF undertook all the statistical analyses and wrote the first draft of the methods and results. $\varnothing \mathrm{L}$ is the principal investigator of the Danish Sex Hormone Register study, advised on analyses, and provided expertise regarding hormonal contraception. LSM provided expertise on ovarian cancer 
epidemiology, advised on the statistical analysis, and wrote the initial programmes for data management. CWS wrote the initial programmes for data management and prepared all the data from the national registries. PCH advised on analyses and provided expertise on hormonal contraception. All authors designed the study, interpreted the results, and approved the final manuscript. The corresponding author attests that all listed authors meet authorship criteria and that no others meeting the criteria have been omitted.

Funding: Supported by a grant (No 11645) from the Novo Nordisk Foundation. The funder had no role in the study design; in the collection, analysis, and interpretation of data; in the writing of the paper; or in the decision to submit the paper for publication.

Competing interests: All authors have completed the ICMJE uniform disclosure form at www.icmje.org/coi_disclosure.pdf and declare: support from the Novo Nordisk Foundation for the submitted work; $\varnothing \mathrm{L}$ reports grants from the Novo Nordisk Foundation, during the conduct of the study, and has been an expert witness in two legal cases in the United States on hormonal contraception and venous thrombosis for the plaintiff in 2011 and 2012; LSM reports grants from the Novo Nordisk Foundation, during the conduct of the study; LSM and CWS became employed by the Novo Nordisk Foundation after the work reported in the manuscript was completed; $\mathrm{PCH}, \mathrm{LI}$, and SF have nothing to disclose.

Ethical approval: The data were analysed and held within the secure data repository at Statistics Denmark. Ethical approval is not required for register based studies according to Danish Research Ethics Committee law (chapter 8, section 3). Nevertheless, approval for the work was obtained from the Danish Data Protection Agency and Health Data Board.

Data sharing: Data sharing is not available.

The lead author affirms that the manuscript is an honest, accurate, and transparent account of the study being reported; that no important aspects of the study have been omitted; and that any discrepancies from the study as planned have been explained.

This is an Open Access article distributed in accordance with the Creative Commons Attribution Non Commercial (CC BY-NC 4.0) license, which permits others to distribute, remix, adapt, build upon this work non-commercially, and license their derivative works on different terms, provided the original work is properly cited and the use is noncommercial. See: http://creativecommons.org/licenses/by-nc/4.0/.

1 United Nations, Department of Economic and Social Affairs, Population Division. (2015). Trends in contraceptive use worldwide 2015 (ST/ESA/SER.A/349). www.un.org/en/ development/desa/population/publications/pdf/family/ trendsContraceptiveUse2015Report.pdf accessed 05/03/2018.

2 GLOBOCAN 2012: Estimated cancer incidence, mortality and prevalence worldwide in 2012. http://globocan.iarc.fr/Pages/ summary_table_site_sel.aspx. Accessed 08/02/2017.

3 Allemani C, Weir HK, Carreira H, et al, CONCORD Working Group. Global surveillance of cancer survival 1995-2009: analysis of individual data for $25,676,887$ patients from 279 population-based registries in 67 countries (CONCORD-2). Lancet 2015;385:9771010. doi:10.1016/S0140-6736(14)62038-9

4 Beral V, Doll R, Hermon C, Peto R, Reeves G, Collaborative Group on Epidemiological Studies of Ovarian Cancer. Ovarian cancer and oral contraceptives: collaborative reanalysis of data from 45 epidemiological studies including 23,257 women with ovarian cancer and 87,303 controls. Lancet 2008;371:303-14 doi:10.1016/S0140-6736(08)60167-1

5 Tsilidis KK, Allen NE, Key TJ, et al. Oral contraceptive use and reproductive factors and risk of ovarian cancer in the European Prospective Investigation into Cancer and Nutrition. $\mathrm{Br}$ J Cancer 2011:105:1436-42. doi:10.1038/bjc.2011.371

6 Vessey M, Yeates D. Oral contraceptive use and cancer: final report from the Oxford-Family Planning Association contraceptive study. Contraception 2013;88:678-83. doi:10.1016/j. contraception.2013.08.008

7 Moorman PG, Alberg AJ, Bandera EV, et al. Reproductive factors and ovarian cancer risk in African-American women. Ann Epidemiol 2016;26:654-62. doi:10.1016/j. annepidem.2016.07.004

8 Bethea TN, Palmer JR, Adams-Campbell LL, Rosenberg L. A prospective study of reproductive factors and exogenous hormone use in relation to ovarian cancer risk among Black women. Cancer Causes Control 2017;28:385-91. doi:10.1007/s10552-016-0840-4

9 Iversen L, Sivasubramaniam S, Lee AJ, Fielding S, Hannaford PC. Lifetime cancer risk and combined oral contraceptives: the Royal College of General Practitioners' Oral Contraception Study. Am J Obstet Gynecol 2017;216:580.e1-9. doi:10.1016/j. ajog.2017.02.002
10 Doherty JA, Jensen A, Kelemen LE, et al, Epidemiology Working Group Steering Committee, Ovarian Cancer Association Consortium Members of the EWG SC, in alphabetical order. Current gaps in ovarian cancer epidemiology: the need for new population-based research. J Natl Cancer Inst 2017;109:djx144.

11 Mørch LS, Skovlund CW, Hannaford PC, Iversen L, Fielding S, Lidegaard $\varnothing$. Contemporary hormonal contraception and the risk of breast cancer. N Engl J Med 2017;377:2228-39. doi:10.1056/ NEJMoa1700732

12 Soini T, Hurskainen R, Grénman S, Mäenpää J, Paavonen J, Pukkala E. Cancer risk in women using the levonorgestrel-releasing intrauterine system in Finland. Obstet Gynecol 2014;124:292-9. doi:10.1097/AOG.0000000000000356

13 Soini T, Hurskainen R, Grénman S, Mäenpää J, Paavonen J, Pukkala E. Impact of levonorgestrel-releasing intrauterine system use on the cancer risk of the ovary and fallopian tube. Acta Oncol 2016;55:1281-4. doi:10.1080/0284186X.2016.1175660

14 Urban M, Banks E, Egger S, et al. Injectable and oral contraceptive use and cancers of the breast, cervix, ovary, and endometrium in black South African women: case-control study. PLoS Med 2012;9:e1001182. doi:10.1371/journal.pmed.1001182

15 Wilailak S, Vipupinyo C, Suraseranivong V, et al. Depot medroxyprogesterone acetate and epithelial ovarian cancer: a multicentre case-control study. BJOG 2012;119:672-7. doi:10.1111/j.1471-0528.2012.03298.x

16 The WHO Collaborative Study of Neoplasia and Steroid Contraceptives. Depot-medroxyprogesterone acetate (DMPA) and risk of epithelial ovarian cancer. Int J Cancer 1991;49:191-5.

17 Mørch LS, Løkkegaard E, Andreasen AH, Krüger-Kjaer S, Lidegaard O. Hormone therapy and ovarian cancer. JAMA 2009;302:298-305. doi:10.1001/jama.2009.1052

18 Lidegaard $\varnothing$, Løkkegaard E, Jensen A, Skovlund CW, Keiding N. Thrombotic stroke and myocardial infarction with hormonal contraception. N Engl J Med 2012;366:2257-66. doi:10.1056/ NEJMoa1111840

19 World Health Organization. International statistical classification of diseases and health related problems, 10 th revision. World Health Organization, 1992.

20 Nielsen LH, Løkkegaard E, Andreasen AH, Keiding N. Using prescription registries to define continuous drug use: how to fill gaps between prescriptions. Pharmacoepidemiol Drug Saf 2008:17:384-8. doi:10.1002/pds.1549

21 Fritz A, Percy C, Jack A, et al, eds. International classification of diseases for oncology. 3rd ed. World Health Organization, 2000

22 Shafrir AL, Schock H, Poole EM, et al. A prospective cohort study of oral contraceptive use and ovarian cancer among women in the United States born from 1947 to 1964 . Cancer Causes Control 2017;28:371-83. doi:10.1007/s10552-017-0876-0

23 Shepherd JH. Revised FIGO staging for gynaecological cancer. BrJ Obstet Gynaecol 1989;96:889-92 doi:10.1111/j.1471-0528.1989.tb03341.x

24 Owens G, Kitchener H. Ovary and fallopian tube. Staging and prognostic grouping. In: O'Sullivan B, Brierley JD, D'Cruz AK, et al, eds. UICC manual of clinical oncology. 9th ed. John Wiley \& Sons, 2015 483-510.1002/9781119013143.ch39.

25 Mutch DG, Prat J. 2014 FIGO staging for ovarian, fallopian tube and peritoneal cancer. Gynecol Oncol 2014;133:401-4. doi:10.1016/i.ygyno.2014.04.013

26 Beral V, Gaitskell K, Hermon C Moser K, Reeves G, Peto R, Collaborative Group On Epidemiological Studies Of Ovarian Cancer. Menopausal hormone use and ovarian cancer risk: individual participant meta-analysis of 52 epidemiological studies. Lancet 2015;385:1835-42. doi:10.1016/S0140-6736(14)61687-1.

27 Kumle M, Weiderpass E, Braaten T, Adami H-O, Lund E, NorwegianSwedish Women's Lifestyle and Health Cohort Study. Risk for invasive and borderline epithelial ovarian neoplasias following use of hormonal contraceptives: the Norwegian-Swedish Women's Lifestyle and Health Cohort Study. Br J Cancer 2004;90:1386-91. doi:10.1038/sj.bjc.6601715

28 Wentzensen N, Poole EM, Trabert B, et al. Ovarian cancer risk factors by histologic subtype: an analysis from the Ovarian Cancer Cohort Consortium. J Clin Oncol 2016;34:2888-98. doi:10.1200/JCO.2016.66.8178

29 McCluggage WG. Morphological subtypes of ovarian carcinoma: a review with emphasis on new developments and pathogenesis. Pathology 2011;43:420-32. doi:10.1097/PAT.0b013e328348a6e7

30 Gottschau M, Mellemkjaer L, Hannibal CG, Kjaer SK. Ovarian and tubal cancer in Denmark: an update on incidence and survival. Acta Obstet Gynecol Scand 2016;95:1181-9. doi:10.1111/aogs.12948

31 Malvezzi M, Carioli G, Rodriguez T, Negri E, La Vecchia C. Global trends and predictions in ovarian cancer mortality. Ann Oncol 2016;27:2017-25. doi:10.1093/annonc/mdw306

Web appendix: Supplemental tables 